\title{
Why bigger isn't always better: Caring for patients in smaller, rural and remote hospitals
}

One of the current obsessions of the NHS is with economies of scale - the notion that healthcare would be safer, faster, cheaper and more efficient if services were provided by larger teams in bigger hospitals or across ever-enlarging networks of organisations. This could be seen as an extension, albeit in a mutated form, of the decades-long drive towards centralisation and specialisation of hospital services. ${ }^{1,2}$ To these ends, over half of all hospitals in England have been closed or merged in the last 20 years, while one of the purposes of sustainability and transformation partnerships (STPs) is to create unprecedented economies of scale at regional level across every type of NHS organisation. ${ }^{2-4}$

One of the consequences of this trend has been to make the smaller hospital seem a near irrelevance in the NHS landscape. Yet smaller hospitals provide care to nearly half the population of England in communities which are frequently rural and/or remote, are more deprived and with a patient cohort that is older and more comorbid than average. ${ }^{5}$ These hospitals arguably face greater challenges than their larger, more urban counterparts. They are more likely to suffer from workforce shortages, a more constrained financial environment and frequently not commissioned to provide the highly specialist services that the public increasingly expects. 5,6 Many of them are plagued by the existential threat of closure, which makes planning and recruitment an even more difficult task. Yet the game for smaller hospitals is not completely over just yet. There is an increasing awareness of their importance internationally, especially in widely geographically dispersed countries such as the USA, Canada and Australia. ${ }^{7}$ In England, The NHS Long Term Plan acknowledged the problems of smaller acute hospitals, including the fact that many 'national standards and policies [are] not appropriately tailored to meet their needs', and pledged to work with trusts on new operating models and developing better links with other parts of local systems. ${ }^{8}$ This has been extended to the consideration of specific needs of smaller, rural and remote hospitals with regard to workforce planning and postgraduate education as part of the forthcoming NHS People Plan.

For some smaller hospitals, their need is urgent and these structural changes cannot come fast enough. In this issue of the Future Healthcare Journal, we brought together some of the key thinkers in the UK and internationally on the problems of smaller hospitals. The notion that 'bigger is better' is challenged and the evidence outlining the critical importance of smaller hospitals in providing high-quality, safe care to their local population is reviewed. In terms of original research, John Browne presents the overall findings of the reconfiguration of acute and emergency services in the Republic of Ireland, while Kevin Fox and colleagues look at the benefits of working in rural and remote settings.,10 Namita Kumar and Adrian Brooke provide an overview of the forthcoming changes to postgraduate training in smaller hospitals, while Rose Singleton gives her personal perspective of training in north Cumbria. ${ }^{11,12}$ Richard Kerr and Chris Thorpe give their perspectives on the future provision of surgery and intensive care medicine, respectively, in smaller hospitals. ${ }^{13,14}$ Dealing with the here and now, Ed Smith recounts the challenges and outcomes of revamping acute services in a smaller hospital under pressure. ${ }^{15}$ Rounding out the issue, Richard Fleet tells of his vision for a new model of smaller hospital, one that is a 'living laboratory' for innovative research and high-quality medical care. ${ }^{16}$

I would like to thank again each of the authors for giving their time and their enthusiasm in advocating for smaller hospitals. Thanks go also to the excellent editorial staff at the Royal College of Physicians for their support in pulling together this special edition of the Future Healthcare Journal.

It remains to say that we hope that the evidence presented here will underline just how important smaller hospitals are in the wider economy. They are deserving of support at every level, if fair and equitable care is to be delivered to all across the NHS. We hope that clinicians and managers will find the edition useful in improving day-to-day care, as well as calling to the attention of our political masters the importance of formulating policies and supporting practices that will able enable smaller hospitals to continue to provide the care that their local populations deserve.

Louella Vaughan

Senior clinical research fellow, Nuffield Trust and consultant physician in acute medicine, The Royal London Hospital

\section{References}

1 The King's Fund. Future organisational models for the NHS Perspectives for the Dalton Review. London: The King's Fund, 2014.

2 Goddard M, Ferguson B. Mergers in the NHS made in heaven or marriages of convenience? London: Nuffield Trust, 1997.

3 Gaynor M, Laudicella M, Propper C. Can governments do it better? Merger mania and hospital outcomes in the English NHS. NBER working paper no 17608. Cambridge: National Bureau of Economic Research, 2011.

4 Boyle S, Lister J, Steer R. Sustainability and transformation plans: how serious are the proposals? A critical review. London: Southbank University, 2017.

5 Monitor. Facing the future: smaller acute providers. London: Monitor, 2014

6 Vaughan L, Edward N, Imison C, Collins B. Rethinking acute medical care in smaller hospitals. London: Nuffield Trust, 2018.

7 Rechel B, Džakula A, Duran A et al. Hospitals in rural or remote areas: An exploratory review of policies in 8 high-income countries. Health Policy 2016;120:758-69.

8 NHS England. The NHS Long Term Plan. London: NHS, 2019.

9 Browne JP. The drivers and impact of emergency care reconfiguration in Ireland: Results from a large mixed-methods research programme. FHJ 2020;7:33-7.

10 Fox K, Corstorphine W, Frazer ] et al. Ten reasons why every junior doctor should spend time working in a remote and rural hospital. FHJ 2020;7:12-4. 
11 Kumar N, Brooke A. Should we teach and train in smaller hospitals? FHJ 2020;7:8-11.

12 Singleton R. The benefits of rural training: Producing the expert generalists of the future. FHJ 2020;7:50-2.

13 Kerr RSC. Surgery in the 2020s: implications of advancing technology for patients and the workforce. FHJ 2020;7:46-9.
14 Thorpe CM. Intensive care medicine in smaller hospitals: here to stay. FHJ 2020;7:28-32.

15 Smith $\mathrm{E}$. The smaller general hospital: Delivering joined up cross specialty working for the benefit of our patients. FHJ 2020;7:22-7.

16 Fleet R. The Canadian Rural Living Lab Hospital: Implementing solutions for improving rural emergency. FHJ 2020;7:15-21.

\section{$=$ Royal College (i) of Physicians}

\section{Lead fellow for social care}

The RCP is appointing a lead fellow for social care, to take up office in summer 2020 for a 3-year term of office. We have created this role due to the growing need to make sure social care provision in the UK is sustainable.

The lead fellow will help us demonstrate and explain the impact of inadequate provision for social care on hospitals and those who work in them.
If you are a fellow of the RCP, have an understanding of social care in the UK, and have the energy and drive to bring about positive change, we want to hear from you.

You can find out more and apply at www.rcplondon.ac.uk/educationpractice/volunteering/vacancylead-fellow-social-care. 